\title{
Huygens: lost - regained - revised. De literair-historische receptie van Constantijn Huygens in de eerste helft van de $19^{\mathrm{e}}$ eeuw
}

\begin{abstract}
From the beginning of professional Dutch Studies (M. Siegenbeek's inauguration as professor eloquentiae hollandicae extraordinarius, 1797) the $17^{\text {th }}$ century Dutch writers P.C. Hooft and Joost van den Vondel are present in Dutch literary studies and literary historiography. The position of Constantijn Huygens, whom the contemporary literary scholars also include in the Grote Vijf (Great Five) of the $17^{\text {th }}$-century Dutch literature (besides Vondel, Hooft, Cats and Bredero), was gradually changing during the $19^{\text {th }}$ century. This article postulates that the reception of Huygens in literary historiography of the first half of the $19^{\text {th }}$ century can be divided into three phases. In the first phase Huygens' works practically disappeared from the Dutch literary landscape. The second phase encompasses growing interest for Huygens as an important historical figure. In the third phase it is possible to observe a shift in critical reception of Huygens: from Huygens as a historical person to Huygens as a poet.
\end{abstract}

Keywords: Constantijn Huygens, Dutch Studies, reception of Dutch literature, literary historiography, $17^{\text {th }}$ century, $19^{\text {th }}$ century

\section{Inleiding}

In het artikel De Gouden Eeuw als ijkpunt van de nationale identiteit: Het beeld van de Gouden Eeuw in verzetsliteratuur tussen 1806 en 1813 parafraseert de letterkundige Lotte Jensen Jeronimo de Vries, de auteur van een van de eerste Nederlandse literatuurgeschiedenissen, schrijvend dat de bloei van de Nederlandse letteren in de zeventiende eeuw te danken was aan vooral één man: Joost van den Vondel (1587-1679): de "Vader, de Vorst, de Fenix der Nederduitsche Poezij" (aangehaald in Jensen 162). "Een goede tweede was Hooft, die op de voet werd gevolgd door Cats, Bredero, Coster, De Groot, Camphuysen en Huygens", schrijft verder Jensen. Constantijn Huygens (1596-1687) wordt in deze reeks van 
de grote zeventiende-eeuwse dichters als de laatste vermeld. Evert Matthijs Wiskerke, de auteur van De waardering voor de zeventiende-eeuwse literatuur tussen 1780 en 1813, schrijft over "de grote vijf, die wij kennen": Vondel, Hooft (1581-1647), Cats (1577-1661), Huygens en Bredero (1585-1618) (266) en van deze grote vijf is Constantijn Huygens (geb. 1596) de jongste Hij is tegelijkertijd ook één van de laatsten van de schrijvers uit de Gouden Eeuw om een plaats te krijgen in de Nederlandse literatuurgeschiedenissen. Het feit dat Huygens tot de Nederlandse literaire canon wordt gerekend is mede te danken aan het werk van negentiende-eeuwse wetenschappers, met name de geschiedkundige T.T.H. Jorissen (1833-1889) en de letterkundige en redacteur J.A. Worp (1851-1917). Dit artikel presenteert de hypothese dat de literair-historische receptie van Huygens' oeuvre in de eerste helft van de negentiende eeuw in drie stadia is verlopen. In elk stadium kan de verandering van de positie van Huygens geplaatst worden in het kader van een wijziging van poëticale opvattingen; van de transitie van het klassieke principe van translatio-imitatio-aemulatio naar de originaliteit van de dichter, dat wordt beschouwd als de manifestatie van het creatieve vermogen van de natie.

\section{Vraagstelling}

Volgens letterkundige George J. Vis, rekende Matthijs Siegenbeek "Hooft, Vondel, Pieter Nieuwland en vele anderen [tot] grote geesten in letteren en wetenschappen, door hun 'stout vernuft, vurigen geest en levendige verbeeldingskracht"" (Vis 396). De door Vis geciteerde woorden van Siegenbeek komen uit diens inaugurele rede als professor eloquentiae hollandicae extraordinarius, voorgedragen in Leiden in 1797. De eerste professionele neerlandicus droeg ermee zijn steentje tot het vormen van de canon van de Nederlandse letteren in statu nascendi bij; misschien accidenteel, maar toch wel.

Van Siegenbeeks "steentje" bleven Hooft en Vondel over als vaste punten in de Nederlandse literatuurgeschiedenis. ${ }^{1}$ Constantijn Huygens, moest nog wachten op zijn waardering als dichter, alhoewel hij in het Nederlandse historische denken wel nadrukkelijk aanwezig was als politicus, staatsman, en zelfs als componist. Ter illustratie: In Mengelwerk, tot fraaije letteren, kunsten en wetenschappen, betrekkelijk (1809) van de Vaderlandsche letteroefeningen zijn door de leraar en predikant Rinse Koopmans (1770-1826) twee verhandelingen gepubliceerd. De eerste daarvan, Constantyn Huygens, Ridder, Heer van Zuylichem enz. als mensch beschouwd, waarin het leven en de carrière van Huygens waren beschreven, da-

${ }^{1}$ In Siegenbeeks Beknopte Geschiedenis der Nederlandsche Letterkunde (1826) zijn Hooft en Vondel als de voornaamste Nederlandse dichters van de zeventiende eeuw vermeld; hetzelfde geldt voor de vroegere Proeve eener geschiedenis der Nederduitsche dichtkunde (1810) van Jeronimo de Vries en ook voor latere letterkundige compendia. 
teert uit het jaar 1801. Het vervolg, Constantyn Huygens, Ridder, Heer van Zuylichem enz. als dichter beschouwd, werd acht jaar later gepubliceerd. Ook Pieter C. Hooft werd destijds in hoofdzaak als geschiedschrijver (auteur van de Nederlandsche Historien) gewaardeerd, meer dan als dichter. Alleen in het geval van het oeuvre van Vondel is er sprake van doorlopende receptie van zijn dichtwerken. ${ }^{2}$

In de Proeve eener geschiedenis der Nederduitsche dichtkunde (1810) schreef Jeronimo de Vries (1776 of 1777-1853), een van de eerste historici van de Nederlandse literatuur, dat Constantijn Huijgens (!) "de vriend van Hooft, Cats en Vondel [was]" (De Vries 177). Verder is er in dit compendium sprake van Huygens' politieke carrière, zijn adellijke titels ("zoo edel van dichtvermogen als van titelen", De Vries 177), brede talenkennis en diverse interesse. Over de dichtwerken van Huygens schreef De Vries, dat ze "de verhevenheid van Vondel en Hooft (...) [misten], en Cats in zoetvloeijendheid en gemakkelijkheid niet (...) [evenaarden], [toch], zullen de niet oppervlakkige, maar aandachtige Lezers zijner Werken, overal eene eigenaardige kracht van zeggen gewaarworden, die men te vergeefs in Vondel, Hooft en Cats zoeken zal" (De Vries 177-178).

Willem J. Hofdijk (1816-1888), de auteur van het populaire handboek Geschiedenis der Nederlandsche letterkunde voor gymnasiën en zelf-onderricht (1857), verbindt Huygens met de Muiderkring (Hofdijk 187) en met het Huis van Oranje-Nassau, waar Huygens als de "Sekretaris van drie achtereenvolgende Stadhouders" (Hofdijk 218-219) diende. In Hofdijks compendium krijgt Huygens als auteur meer aandacht:

Hy was vlug van bevatting, geestig, levendig, en zoo kort van uitdrukking, dat hy er wel eens duister door wordt. Maar hy stond den beste ter zij in heerschappij over de taal, en geeft daardoor zijne vaerzen een lossen levendigen gang, die de lezing altoos aangenaam maakt (Hofdijk 1857: 219).

In de Kleine geschiedenis der Nederlandsche letteren geschreven in 1891 door Leidse hoogleraar (en tegelijkertijd prozaschrijver) Jan ten Brink (18341901) heeft "Constantin Huygens" (Ten Brink 183) zijn eigen hoofdstuk "gekregen", zulks in tegenstelling tot bijvoorbeeld Jacob Cats, die samen met andere dichters uit "Dordtrecht" (Ten Brink 177) werd besproken. In dat hoofdstuk werd Huygens' oeuvre parallel met zijn biografie gepresenteerd. Ten Brink besluit de beschrijving met de volgende woorden:

al zijn werken (...) getuigen nopens die zeldzaam gelukkige overeenstemming van uitwendige glorie en innerlijke voortreffelijkheid; Huygens wordt hierdoor een man van eerbiedwekkende harmonie in woord, daad en schrift (Ten Brink 188-189).

${ }^{2}$ De eerste biografische verslagen over Vondel dateren al uit de zeventiende eeuw (Gerard Brandt de Jonge, 1626-1685 Het leven van Joost van den Vondel, 1682). Vondels dichtwerken zijn in de hele achttiende eeuw gepubliceerd, sommige toen zelfs voor de eerste keer (bijv. Zegezang ter eeren van Frederik Hendrik Prince van Oranje, eerste uitgave 1721), ook voor de neerlandici van het eerste uur als De Vries en Siegenbeek fungeerde Vondel als vast referentiepunt in de Nederlandse literatuur. 
Deze drie portretten van Constantijn Huygens zijn gepubliceerd in respectievelijk 1810, 1857 en 1891, dus gemiddeld steeds met een veertigjarige pauze. Zelfs op basis van die fragmenten is het mogelijk te veronderstellen dat de waardering van Huygens' oeuvre in de loop van de negentiende eeuw niet alleen toenam maar ook veranderde: vanuit historische naar literaire. In dit artikel zal ik proberen om de dynamiek van die toenemende waardering voor de werken van Huygens te tonen.

De bronnen voor de bibliografische basis van deze bijdrage zijn de digitale catalogus van de Koninklijke Bibliotheek, Den Haag (beschikbaar op het internetadres http://opc4.kb.nl) en de website van de Digitale Bibliotheek voor de Nederlandse Letteren (http://www.dbnl.org). Hoewel deze bronnen sensu stricto geen bibliografieën zijn, bestaat er bij mijn weten geen volledige bibliografie van de Nederlandse boeken van vóór het jaar 1833 toen Brinkman's cumulatieve catalogus van boeken begon te verschijnen.

Er bestaan wel teksten, waarin de waardering voor de zeventiende-eeuwse schrijvers (J.P. Naef, De waardering van Gerbrand Adriaenszoon Bredero, 1960) of voor de zeventiende-eeuwse literatuur (E.M. Wiskerke, De waardering voor de zeventiende-eeuwse literatuur tussen 1780 en 1813, 1995) alsook verhandelingen betreffende de beeldvorming van de zeventiende eeuw in de negentiende-eeuwse naslagwerken (Gert-Jan Johannes “'Zoo is overdrijving de ziekte van elke eeuw'. Het beeld van de 17 de eeuw in de 19 de-eeuwse literatuurgeschiedenissen voor schoolgebruik en zelfstudie", 2002). Over de poëticale opvattingen in Nederland aan het einde van de achttiende en in het begin van de negentiende eeuw schreef Jan Oosterholt in De ware dichter. De vaderlandse poëticale discussie in de periode 1775-1825 (1998). Zowel Wiskerke als Johannes, en Oosterholt ruimen veel plaats in voor Hooft, Vondel, en Cats. Huygens heeft in hun teksten echter een marginale plaats (net zoals in de vroegere negentiende-eeuwse literaire naslagwerken).

\section{Verloren?}

Constantijn Huygens overleed in het jaar 1687. Het laatste van zijn werken die in de zeventiende eeuw werden gepubliceerd, Cluys-werck, dateert uit het jaar 1683. In de catalogus van de Koninklijke Bibliotheek (http://www.kb.nl) worden er slechts drie teksten van Huygens vermeld die in de achttiende eeuw waren uitgegeven, alhoewel twee ervan tweemaal. Ten eerste gaat het om Huygens' eigen werken De zee-straet van 's Graven-hage op Schevening gepubliceerd in 1711 en 1729 en De herstelde prins, tot stadt-houder ende kapitein generaal van de Vereenigde Nederlanden, uitgegeven in 1749. Daarnaast werd de 'co-productie' van Huygens en Gysbert de Crester Beschryvinge van 's-Gravenhage twee maal uitgegeven: in 1711 en 1729 (tweede druk). Ter vergelijking: in dezelfde tijd werden tien werken van Pieter C. Hooft gepubliceerd. Dat lijkt een dalende populariteit van de zeventiende-eeuwse auteurs tijdens de verlichting te suggereren. Tegelijkertijd zijn er echter 53 nieuwe 
edities van de werken van Jacob Cats en meer dan 100 nieuwe uitgaven van Vondel verschenen, wat een tegenovergestelde tendentie in de receptie van de zeventiendeeeuwse literatuur lijkt, tenminste kwantitatief, te bevestigen.

Niet alleen het feit dat Matthijs Siegenbeek Huygens niet tot de grote Nederlandse schrijvers heeft gerekend, getuigt van Huygens' eerder marginale positie in de achttiende eeuw. De Digitale Bibliotheek voor de Nederlandse Letteren (http:// www.dbnl.org) vermeldt in Huygens' profiel slechts één titel secundaire literatuur, daterend uit de jaren 1701-1800. Dat is het overigens buitengewoon interessante Panpoëticon Batavum, ${ }^{3}$ geschreven door de Amsterdamse apotheker, geleerde en geletterde Lambert Bidloo (1638-1724) en gepubliceerd in 1720. Ter vergelijking, op dezelfde internetpagina zijn er zeven teksten over Hooft en zeventien over Vondel uit dezelfde periode vermeld.

Een van de mogelijke verklaringen van de afwezigheid van Huygens' werken op de achttiende-eeuwse boekenmarkt kan de kleine belangstelling voor (of zelfs kritiek op) de zeventiende-eeuwse literatuur zijn. In het kader van de toenmalige poëticale opvattingen konden de innovatieve gedichten van Huygens als te origineel en (tenminste) controversieel worden gezien. Klassieke teksten of hun Franstalige navolgingen werden destijds kennelijk meer op prijs gesteld. In de vierdelige Proeve van taal-en dichtkunde: In vrijmoedige aanmerkingen op Vondels vertaalde Herscheppingen van Ovidius (1730) gebruikt letterkundige, historicus en taalkundige Balthazar Huydecoper (1695-1778) Vondels vertaling van Ovidius' Metamorphosen om te "laten zien hoe gevaarlijk een kritiekloze imitatie van inheemse dichters kan zijn" (Oosterholt 148). Ook dokter, ambtenaar en geletterde Jan Macquet (1731-1798) stelt in zijn driedelige Proeven van dichtkundige letteroefeningen (1780-1786) de (Griekse/Romeinse) klassieken voor als de beste voorbeelden ter navolging door de aanstormende literaire talenten, die, volgens Oosterholt, niet in staat zouden zijn geweest om "de gebreken in het werk van de zeventiende-eeuwse dichters te onderscheiden van de fraaie passages" (148).

\section{Teruggewonnen}

De voorgenoemde Proeve eener geschiedenis der Nederduitsche dichtkunde (1810) van Jeronimo de Vries lijkt de eerste negentiende-eeuwse tekst te zijn waarin de werken van Huygens werden besproken en zou tot 1822 ook de enige dergelijke tekst blijven. Toch stijgt in de laatste decennia van de achttiende en in het begin van de negentiende eeuw de waardering van de zeventiende-eeuwse

${ }^{3}$ Zoals de volledige titel van dit werk Panpoëticon Batavum, kabinet, waar in de afbeeldingen van voornaame Nederlandse dichteren, verzameld, en konstiggeschilderdt door Arnoud van Halen, en onder uytbreyding, en aanmerkingen, over de Hollandsche rym-konst verraadt, is de tekst van Bidloo een overzicht van de belangrijkste Nederlandse literatoren. Het werk vertoont gelijkenis met Het schilder-boeck van Karel van Mander (1604). 
schrijvers. In de Theorie der schone kunsten en wetenschappen (1778-1780) postuleert dichter en pedagoog Hiëronymus van Alphen (1746-1803) dat de Nederlandse dichtkunst minder prominent is dan de poëzie van de omringende landen (Wiskerke 367). Volgens Van Alphen bevindt zich de Nederlandse literatuur in het stadium van verval, veroorzaakt door, in Oosterholts formulering, "de bedorven smaak van de moderne dichter" (157). Nog steeds binnen het kader van het creatieve principe van translatio - imitatio - aemulatio stelt Van Alphen goede voorbeelden om na te volgen - Vergilius en Horatius, maar ook Milton of Pope (Oosterholt 158). Van Alphens tegenstander Jeronimo de Bosch (1740-1811), de auteur van de Verhandeling over de regelen der dicht-kunde (1783) pleit voor het actualiseren van poëticale voorbeelden, door het hanteren van goede literaire principes, zoals het vroeger werd gedaan. Het verval van de Nederlandse letteren is volgens hem veroorzaakt door het verlaten van de weg van Hooft en Vondel, dat is de navolging van de klassieken. In het geval van De Bosch kan er geen sprake zijn van de navolging van Hooft en Vondel, maar van hun poëticale principes (Wiskerke 368).

Een wezenlijk verschil tussen de bovengenoemde verhandelingen door zowel Van Alphen als De Bosch en De Vries' Proeve eener geschiedenis der Nederduitsche dichtkunde is het feit dat De Vries de literaire verschijnselen in het kader van de nationale geschiedenis plaatst. Het werk van De Vries kan ook worden beschouwd als een verhandeling bestemd voor een groter ook in de geschiedenis en andere zaken belangstellend publiek dan alleen de (toekomstige) adepten van de dichtkunst. Misschien daarom is er in Proeve eener geschiedenis plaats voor Huygens, wiens poëzie wel een minder goed voorbeeld ter navolging zou kunnen zijn, maar wiens plaats in de zeventiende-eeuwse politieke en artistieke (niet alleen literaire) netwerken niet meer kon worden verzwegen.

Bovendien kan er vanaf de jaren twintig van de negentiende eeuw sprake zijn van de stijgende belangstelling voor de zeventiende eeuw als de Gouden Eeuw van de Nederlandse natie (alhoewel in de zeventiende eeuw echter geen sprake kon zijn van de Nederlandse natie ${ }^{4}$...). Jacob A. Worp, de tekstbezorger van de eerste complete uitgave van Huygens' dichtwerken (1892-1899), vermeldt een bericht betreffende een veiling van "eene menigte handschriften en teekeningen van het geslacht Huygens" (Huygens Gedichten IX) dat in het nummer van de Algemene Konst- en Letterbode van 19 juli 1822 is gepubliceerd. Huygens' manuscripten en tekeningen zijn op 17 februari 1823 onder de hamer gebracht en respectievelijk voor 1300 en 400 gulden verkocht. Later werd bekendgemaakt dat de koper van de handschriften, de heer S. Iz. Wisselius, de collectie "op last en voor rekening van Z.M. den Koning" (Huygens Gedichten X) kocht. Enerzijds kan het aankopen

${ }^{4}$ De kwestie van de Nederlandse natievorming in de zeventiende eeuw wordt behandeld in mijn artikel "(De mythische) 'Batavia' in de Gouden Eeuw - een poging tot (re)constructie: Het scheppen van de nationale ruimte" gepubliceerd in Neerlandica Wratislaviensia XXIII (2014): 53-73. 
van Huygens' manuscripten ervan getuigen dat het Koninklijk Huis belangstelling lijkt te hebben gehad voor vaderlandse geschiedenis. Anderzijds lijkt des konings algemene interesse voor voorwerpen met historische waarde (de nalatenschap van een groot staatsman en secretaris van 's konings voorvaderen, niet noodzakelijk die van een groot schrijver) een even plausibele hypothese te zijn.

Ook in 1822 wordt het derde deel van Pieter G. Witsen-Geysbeeks Biographisch anthologisch en critisch woordenboek der Nederduitsche dichters gepubliceerd. Dit omvatte de auteurs, wier familienamen met de letters van HAE tot IPE begonnen. Het samenvallen van de uitgavedatum en de datum van de veiling lijkt puur toeval te zijn, en wel om twee redenen. Ten eerste moet Witsen-Geysbeek zijn woordenboek al vroeger hebben voorbereid en is het onwaarschijnlijk dat hij de voornoemde manuscripten gebruikte. Ten tweede wordt in het woordenboek zelf alleen gerefereerd aan de vroegste (meestal zeventiende-eeuwse) edities van Huygens' werken, de manuscripten zijn echter niet vermeld. Het artikel in Witsen-Geysbeeks woordenboek bleef de meest volledige biografie van Huygens tot het jaar 1867 (Abraham J. van der Aa, Biographisch woordenboek der Nederlanden. Deel 8. Tweede stuk) of zelfs 1871 (Theodoor Jorissen, Constantijn Huygens. Studiën).

Toen in 1892 het eerste deel van de complete editie van Huygens' gedichten werd gepubliceerd, was het al 205 jaar na zijn dood. Het is merkwaardig dat de manuscripten, aangeschaft in 1823, 69 jaar moesten 'rijpen' en de brieven nog 19 jaar langer, tot de publicatie van de edities van Jacob A. Worp uit de jaren 1892-1899 (Gedichten, 9 delen) en 1911-1917 (Briefwisseling, 6 delen). De (her) ontdekking van Huygens' handschriften leidde dus niet tot hun directe publicatie, wat er een bewijs voor lijkt te zijn dat de handschriften eerder als een collectie historische voorwerpen dan als literaire werken waren aangeschaft. Maar niet alleen dat. Toen Willem Bilderdijk de nieuwe editie van Korenbloemen wilde voorbereiden, werd hem de toegang tot deze manuscripten geweigerd, aldus Worp (Huygens Gedichten XI). Zelfs één van de herontdekkers van Huygens, Theodoor Jorissen, "schreef zijn werk over Constantin Huygens (1871) zonder te weten, welk een schat er in zijne nabijheid verborgen was" (Huygens Gedichten XI). Een van de eerste monografieën over de dichter werd dus volledig geschreven zonder het raadplegen van zijn handschriften.

Zowel de langere pauze tussen de literatuurgeschiedenis van De Vries en de (her)ontdekking van Huygens als het wachten met uitgeven van de handschriften van de dichter getuigt er echter ook weer niet van dat er geen belangstelling voor hem was in de eerste helft van de negentiende eeuw. Zowel de aankoop van Huygens' handschriften alsook de publicatie van Witsen Geysbeeks biografisch woordenboek leidden juist tot het in beweging brengen van biografisch-georiënteerde onderzoekingen naar Constantijn Huygens, waarvan de reeds genoemde monografie Constantijn Huygens. Studiën (1871) door Theodoor Jorissen als het meest representatieve voorbeeld kan dienen. Na 1823 bleven de werken van Huygens verschijnen, gepubliceerd als afzonderlijke teksten of in collecties: in 1824 
(Batava Tempe, 'T Voor-hout van 's Gravenhage; Korenbloemen), 1841 (Cluyswerck), 1852 (Uit de Korenbloemen), 1865 (Korenbloemen deel 1 en 2). Er is ook een artikel over Huygens te vinden in Van der Aa's al genoemde Biographisch woordenboek der Nederlanden (Deel 8, tweede stuk, 1867).

\section{Gerevideerd}

Voor Hofdijk was Vondel de prins "onzer dichteren", de werken van Hooft waren deftig en zangerig en die van Bredero dichtbij het mensenleven. Huygens mocht volgens Hofdijk vol geest en vernuft zijn, maar het was Jacob Cats, die naar Hofdijks woorden de waardering van de algemene publiek genoot (Hofdijk 222). De positie van Cats zal in de tweede helft van de negentiende eeuw dalen en die van Huygens stijgen, maar nog belangrijker dan hun plaats in literatuurgeschiedenis schijnt de verandering in de kritische oriëntatie, die ook in deze periode heeft plaatsgevonden.

Worp schrijft in zijn inleiding tot de eerste complete uitgave van Huygens gedichten dat "[h] et ... hier niet de plaats [is], om te onderzoeken, of Huygens het ideaal, waarnaar hij als dichter streefde, nabij is gekomen" (Huygens Gedichten VIII), de editeur heeft de dichter genomen zoals hij was: "met zijne kernachtige, doch meermalen gewrongene wijze van uitdrukking, met zijne scherpe opmerkingsgave, zijne grootemenschenkennis, zijne ernstige satire, zijn diep nadenken, ..." (Huygens Gedichten VIII). Verder doet Worp een poging om het oeuvre van Huygens in een bredere context te plaatsen, waarvan de literaire aspecten belangrijker lijken te worden dan de biografische.

Het begin van de verandering aangaande literatuurgeschiedenissen kan worden vastgesteld door de accentuering in de tekst van het genoemde literair-historische compendium. In de volgende stadia van de ontwikkeling van literaire historiografie (die met de ontwikkeling van literatuurwetenschap gepaard gaan) kan een verschuiving van aandacht voor de persoon van de auteur (biografisme en waardering als historische persoon) naar aandacht voor de tekst (analyse van de inhoud) worden geobserveerd. Hoewel in Willem J.A. Jonckbloets Geschiedenis der Nederlandsche letterkunde (eerste uitgave, 2 delen, 1868-1872) de biografieën van de auteurs nog steeds als organiserende factor dienen, gebruikt de literatuurhistoricus specifieke fragmenten van de teksten om zijn claims te beargumenteren. Wat Constantijn Huygens betreft, zijn dat meestal citaten uit zeventiende-eeuwse edities van zijn oeuvre, ongeacht de oorspronkelijke taal (Latijn, Frans, Nederlands), waarin de geciteerde passage werd geschreven.

De in 1823 aangeschafte handschriften van Huygens' teksten werden in 1872 opnieuw gevonden - dus her-herontdekt - op de zolder van het Trippenhuis (de bibliotheek van de Koninklijke Akademie van Wetenschappen) en door Johannes C.G. Boot en Jorissen gecatalogiseerd (Huygens Gedichten XI). Vanaf de jaren 
tachtig van de negentiende eeuw zijn er meerdere kritische edities van Huygens' werken gepubliceerd en ook besproken en kritisch beoordeeld in literaire tijdschriften zoals bijvoorbeeld De Gids. De nieuwe uitgaven (Worps complete editie van de Gedichten kan hier als voorbeeld dienen) kregen vaak een aantal parateksten mee, zoals voor- en nawoorden, kritische of verklarende aantekeningen (voetnoten) en de vermeldingen van bronnen. Deze parateksten getuigden niet alleen van stijgende belangstelling voor Huygens' oeuvre, maar ook van de temporele afstand tussen de originelen, hun eerste uitgaven en deze nieuwe edities. De bronnenvermeldingen (zowel naar vroegere edities van teksten alsook naar kritische verhandelingen over Huygens en zijn oeuvre) kunnen als bewijzen van wetenschappelijke i.e. literair-kritische en historische interesse dienen. De vooren nawoorden alsook de verklarende voetnoten zijn vooral contextualiserend van aard, zodat zijn teksten zo even (on)begrijpelijk mogelijk zouden zijn voor de contemporaine (i.e. negentiende-eeuwse) lezers als voor hun zeventiende-eeuwse tegenhangers.

\section{Verstevigd (in plaats van een conclusie)}

De receptie van Huygens' oeuvre in de negentiende eeuw kan als een voorbeeld dienen van een dynamische receptie, waarop aspecten als de dominerende poëticale opvattingen van een bepaalde tijd op de waardering van de oude(re) literaire werken een grote invloed hebben uitgeoefend. Na de daling van de belangstelling voor de literaire productie van Huygens in de achttiende eeuw, begon de interesse voor zijn teksten vanaf de jaren 1820 weer te groeien. Deze stijgende belangstelling voor Huygens' werken is begonnen met het plaatsen van zijn oeuvre in de nationale context (De Vries) en ging gepaard met de verandering in de (literair-) kritische behandeling van deze teksten.

In de jaren veertig van de negentiende eeuw pleitte dichter, letterkundige en historicus Everhardus J. Potgieter (1808-1875) voor een standbeeld van Huygens op het eilandje in de Hofvijver (Kuik 168). Potgieters appel leek het enige aspect van de buiten-literaire receptie van Huygens gedurende de daaropvolgende vijftig jaar. In 1896 werd bij gelegenheid van de dichters $300^{\mathrm{e}}$ geboortedag, aan de Scheveningseweg een borstbeeld onthuld, uitgerekend een borstbeeld, omdat Constantijn Huygens als dichter van de tweede garnituur niet in aanmerking kwam voor een standbeeld. Volgens de feestredenaar - taalkundige en medioneerlandicus Jacob Verdam is "een borstbeeld van Huygens in overeenstemming met de rang dien wij hem in onze dichtergalerij toekennen" (aangehaald in Kuik 169).

Toch wordt in de letterkundige compendia uit de tweede helft van de negentiende eeuw en uit de eerste drie decennia van de twintigste eeuw de hoge positie van Huygens verstevigd. Zowel bij de voornoemde Jan ten Brink (in diens Kleine geschiedenis der Nederlandsche letteren, 1877, en Geschiedenis van de Neder- 
landsche letteren, 1897) alsook bij Gerrit Kalff (Geschiedenis der Nederlandsche letterkunde, 1906-1912) en Jan te Winkel (De Ontwikkelingsgang der Nederlandsche letterkunde, 1908-1921 en 1921-1927) wordt de lezer geen enkele twijfel gegund dat Constantijn Huygens in deze compendia moest worden opgenomen als een auteur van even groot belang als Vondel of Hooft. De dichter Huygens was 'regained' en heeft zijn standbeeld in de literatuurgeschiedenis(sen) gekregen.

\section{Bibliografie}

Aa, Abraham J. van der (1867): Biographisch woordenboek der Nederlanden. Deel 8. Tweede stuk. Haarlem: J.J. van Brederode. Laatst geraadpleegd op 9.02.2017 (http://www.dbnl.org/tekst/ aa_001biog10_01/).

Bidloo, Lambert (1720): Panpoëticon Batavum, kabinet, waar in de afbeeldingen van voornaame Nederlandse dichteren, verzameld, en konstiggeschilderdt door Arnoud van Halen, en onder uytbreyding, en aanmerkingen, over de Hollandsche rym-konst. Amsterdam: Andries van Damme. Laatst geraadpleegd op 9.02.2017 (http://www.dbnl.org/tekst/bidl002panp01_01/ bid1002panp01_01.pdf).

Brandt, Geeraardt (1932): Het leven van Joost van den Vondel. Leendertz, P. Jr. (ed.). 's-Gravenhage: Martinus Nijhoff.

Brink, Jan ten (1891): Kleine geschiedenis der Nederlandsche letteren. $3^{\mathrm{e}}$ druk. Haarlem: Erven F. Bohn.

Brink, Jan ten (1897): Geschiedenis der Nederlandsche Letterkunde. Amsterdam: Uitgevers-Maatschappy „Elsevier”.

Hofdijk, Willem J. (1857): Geschiedenis der Nederlandsche letterkunde. Amsterdam: Gebroeders Kraay. Laatst geraadpleegd op 6.02.2017 (http://www.dbnl.org/tekst/hofd001gesc01_01/).

Huygens, Constantijn (1892-1899): Gedichten. 9 delen. Worp J.A. (ed.). Groningen: J.B. Wolters.

Huygens, Constantijn (1911-1917): Briefwisseling. 6 delen. Worp J.A. (ed.). 's-Gravenhage: Martinus Nijhoff.

Jensen, Lotte (2012): "De Gouden Eeuw als ijkpunt van de nationale identiteit: het beeld van de Gouden Eeuw in verzetsliteratuur tussen 1806 en 1813". In: De zeventiende eeuw 28, 2: 161175.

Jonckbloet, Willem J.A. (1868-1872): Geschiedenis der Nederlandsche letterkunde. 2delen. Groningen: J.B. Wolters.

Johannes, Geert-Jan (2004): "Zoo is overdrijving de ziekte van elke eeuw. Het beeld van de 17de eeuw in de 19de-eeuwse literatuurgeschiedenissen voor schoolgebruik en zelfstudie". In: $\mathrm{Ne}$ derlandse Letterkunde 7: 28-60.

Jorissen, Theod[oor] (1871): Constantijn Huygens. Studiën. Arnhem: Stoomdrukkerij Loman, Kirberger en van Kesteren. Laatst geraadpleegd op 9.02.2017 (https://ia800204.us.archive.org/30/ items/constantinhuyge00jorigoog/constantinhuyge00jorigoog.pdf).

Kalff, Gerrit (1906-1912): Geschiedenis der Nederlandsche letterkunde. 7 delen. Groningen: J.B. Wolters.

Koopmans, Rinse (1809): "Constantyn Huygens, Ridder, Heer van Zuylichem enz. als mensch beschouwd". In: Vaderlandsche letteroefeningen. Jaargang 1809: 141-163. Laatst geraadpleegd op 8.02.2017 (http://www.dbnl.org/tekst/_vad003180901_01/_vad003180901_01_0243.php).

Koopmans, Rinse (1809): “Constantyn Huygens, Ridder, Heer van Zuylichem enz. als dichter beschouwd". In: Vaderlandsche letteroefeningen. Jaargang 1809: 181-205. Laatst geraadpleegd op 8.02.2017 (http://www.dbnl.org/tekst/_vad003180901_01/_vad003180901_01_0250.php). 
Kuik, C.J. (1980): Helden op sokkels. Literaire standbeelden in Nederland. Baarn: Bosch \& Keuning n.v.

Naeff, Jan Paulus (1960): De waardering van Gerbrand Adriaenszoon Bredero. Gorinchem: J. Noorduijn en zoon.

Oosterholt, Jan (1998): De ware dichter. De vaderlandse poëticale discussie in de periode 17751825. Assen: Van Gorcum. Laatst geraadpleegd op 16.06.2017 (http://www.dbnl.org/tekst/ oost051ware01_01/index.php).

Siegenbeek, Matthijs (1826): Beknopte geschiedenis der Nederlandsche letterkunde. Haarlem: Erven van François Bohn. Laatst geraadpleegd op 8.02.2017 (http://www.dbnl.org/arch/sieg002bekn01_01/pag/sieg002bekn01_01.pdf\#page=51).

Vis, George J. (1993): “23 September 1797: De doopsgezinde predikant M. Siegenbeek inaugureert te Leiden als 'professor eloquentiaeholandicae extraordinarius' - De professionalisering van de neerlandistiek". In: Schenkenveld-Van der Dussen, Maria A. (ed.): Nederlandse Literatuur, een geschiedenis. Groningen: Martinus Nijhoff, 395-402.

Vries, Jeronimo de (1810): Proeve eener geschiedenis der Nederduitsche dichtkunde. Twee delen. Amsterdam: Johannes Allart. Laatst geraadpleegd op 9.02.2017 (http://www.dbnl.org/tekst/ vrie032proe01_01/).

Winkel, Jan te (1922-1927): De Ontwikkelingsgang der Nederlandsche Letterkunde. 7 delen. Haarlem: Erven F. Bohn.

Wiskerke, Evert Matthijs (1995): De waardering van de zeventiende-eeuwse literatuur tussen 1780 en 1813. Hilversum: Verloren.

Witsen-Geysbeek, Pieter G. (1822): Biographischanthologisch en critisch woordenboek der Nederduitsche dichters. Deel 3 HAE-IPE. Amsterdam: C.L. Schleijer. Laatst geraadpleegd op 9.02.2017 (http://www.dbnl.org/tekst/wits004biog03_01/wits004biog03_01_0112.php).

Przemysław A. Paluszek $(* 1985)$ is in 2009 afgestudeerd aan de Universiteit van Wrocław als neerlandicus. Tussen 2010 en 2016 was hij doctorandus bij diezelfde universiteit. Na een periode (2013-2016) bij de KU Lublin, werkte hij in het academiejaar 2016/2017 bij de A. Mickiewicz Universiteit in Poznań en is vanaf october 2016 verbonden aan de Universiteit van Opole, waar hij in het kader van de specialisatie Duits met Nederlands colleges Nederlandse Taalverwerving aan de studenten Germanistiek geeft.

e-mail: p.a.paluszek@gmail.com 